\title{
Employing Search Engine Optimization Techniques in Online News Articles
}

\author{
Dimitrios Giomelakis ${ }^{1}$, Andreas Veglis ${ }^{1}$ \\ ${ }^{1}$ School of Journalism and Mass Communications, Aristotle University of Thessaloniki, Greece \\ Correspondence: Dimitrios Giomelakis, Aristotle University of Thessaloniki, Greece.
}

Received: February 15, 2015 Accepted: March 11, 2015 Online Published: March 31, 2015

doi:10.11114/smc.v3i1.683 URL: http://dx.doi.org/10.11114/smc.v3i1.683

\begin{abstract}
Internet technologies have changed basic journalistic work processes and brought about new modes of producing and consuming news content. As long as major search engines continue to drive a great deal of traffic to news Web sites or remain the primary entry point for many of them, factors such as visibility and high ranking on search engines results pages remain crucially important. This paper examines the issue of Search Engine Optimization (SEO) and its implementation on online journalism. According to research (Richmond, 2008), SEO has a significant impact on this field and its knowledge can be a useful tool for journalists whose work appears online. The principal purpose of this article is to outline a framework of suggested practices that can make journalistic work and Internet journalism generally, more effective and contemporary.
\end{abstract}

Keywords: search engine optimization, SEO, search engines, online journalism, news websites, search, news articles

\section{Introduction}

The rise of the Internet during the last two decades has extremely affected media organizations and challenged traditional journalism. Basic journalistic work processes such as newsgathering, news production and distribution, as well as the way people consume news have changed to a great extent (Chung, 2008; Spyridou \& Veglis, 2008). While new technologies are developing rapidly, different news sources have emerged including search engines, online news aggregators, social networks and citizen journalism.

The development of World Wide Web from early years to Web 2.0 in parallel with the new Internet technologies and growth of contemporary search engines over the last decade, have brought significant changes in Web content such as user-generated content, metadata or social web. Furthermore, search technology itself evolved over the last years. There is no question that the Internet is currently one of the most popular sources of news and the preferred choice for many people (Pew Research Center, 2013). As we will see a large part of Internet traffic depends to a great extent on the search engines, and also, a lot of people use them as a basic tool of navigation and filter for news (Safran, 2013; Newman and Levy, 2014). It's a common practice for users to choose results only from the first page of search results. While more and more Web sites are indexed by search engines and compete with each other, it's obvious that factors as the highest ranking and top of the results page become increasingly essential for an online media business and consequently, for online articles (Dick, 2011; Spyridou \& Veglis, 2012).

Visibility of a site through Web searches has become a necessary ingredient for the survival of the site (Galitsky and Levene, 2004). The transition to digital journalism means different things for journalists. On the Internet with a wealth of news Web sites, the rapid dissemination of information and also the existence of a "culture of the click" (Anderson, 2009), the aim is a story to find readers also through the search engines and news aggregators. Besides, journalists are writing to be read and these days that means ensuring that their stories are found by search engines (Richmond, 2008).

Media organizations and thus journalists need to be aware of Web technologies and at the same time respond to new reading tendencies or information consumption habits in order to make online news sites better and have a better chance of being read. The aim of this paper is two-fold: on the one hand, to make media scholars, journalists or other digital newsworkers understand what search engine optimization is and its impact on online journalism whilst on the other hand, to outline a general framework of guidelines that will help media professionals produce and distribute the news in a synchronized and more effective manner. The basic approach is related to the chances provided to news organizations through the utilization of search engines and Web search in general. As the marketplace evolves there is a constant need 
for new reviews of current thought and practice. The reason behind this paper was the absence of an equivalent work in the academic literature adapted on media work processes in newsrooms.

The rest of the paper is organized as follows: In section 2 there is a critical synthesis of literature and previous research. Along with a theoretical background, it is discussed extensively the subject of Search Engine Optimization and its impact on journalism as well as the role of social media in this field. The framework of suggested practices (guidelines) and the contribution to academic knowledge is described in section 3. Finally, section 4 includes the conclusions as well as future extensions of this work.

\section{Literature Review}

\subsection{Definition of Search Engine Optimization}

Search Engine Optimization (or SEO-acronym) pertains to the practices aimed to increase the visibility and traffic (visitors) a Web site or a Web page receives from organic (Note 1) search engine results (Potts, 2007; Ledford, 2009). In general, the higher and more frequently a site appears in the search engine results Page (SERP), the more visitors it will receive from the search engine's users. In other words, a process that takes into account the evaluation criteria of search engines through different strategies. SEO constitutes a part of Search Engine Marketing (SEM) which defines the steps taken to organically grow a site's relevancy by building links, writing strong content or submitting to search sites (Potts, 2007). Furthermore, it is one of the leading and most influential activities in the field of online marketing (Nigro, et al., 2012).

\subsection{Why SEO is Important?}

The majority of Internet traffic depends to a great extent on the biggest search engines. According to Conductor's research (Safran, 2013) natural search is responsible for nearly half (47 percent) of all visits. Furthermore, a survey on the behavior of users from iProspect (2006) showed that 90 percent of search engine users never read past the third page of results, and 62 percent of them click on a search result within the first page. A recent study from Chitika (2013) confirms the importance of Google search result positioning and thus SEO. According to data, the top listing in Google's organic search results receives 32,5 percent of the traffic, compared to 17,6 percent for the second position and 11,4 for the third. In addition, sites listed on the first Google search results page generate 92 percent of all traffic from an average search.

One of the biggest advantages of SEO, which is based on clear Web page optimization, is the long-term durability and permanence of results. The results of a well executed, legitimate SEO campaign can last a long time and take much longer to fade than that of a pay per click (Note 2) campaign (Hoel, 2013). Good search engine optimization can also mean good marketing and can influence or contribute to the success of brand management and the communication of a corporate identity (Lieberam-Schmidt, 2010). As Matt Cutts (2012) describes in his Google's blog article, it is about creative ways to make a site more compelling, which can help both search engines and social media. A great site has usually greater awareness on the Web, which can translate into more people visiting or linking to. The most egregious and false myth about search engines is that attaining a top position in the organic results requires actually paying the search sites. On the contrary, a top spot requires worthy content coupled with time, effort, and skill (Potts, 2007). While more and more Web sites compete with each other to gain a high market share, everyone can understand that is essential for a Web page to be accessible and rank higher in SERP.

\subsection{SEO and Online Journalism}

Despite Search Engine Optimization appeared almost in parallel with the creation of the first search engines (Dover, 2011), SEO practice entered newsrooms within the last few years as an emerging production norm and practice, having a direct impact on journalistic workflow and creating new challenges for media professionals. News organizations redirect and redefine the news making process, among other things, around clickstream and SEO notion of news due to the convergence dynamics and the new challenges that face journalism as a whole (Spyridou \& Veglis, 2012). In the third stage of the evolution of online content, original news content is designed specifically for the new medium (Pavlik, 1997). SEO can be a key requirement for some projects to be viewed as successful, especially for content based sites (Charlton, et al., 2008). It is true that journalism has always had a certain formula. The five -Ws- that any good story must have; the inverted pyramid structure; or working within the constraints of the publication's style book. Richmond (2008) argues that SEO rules are as important as any of these and actually improve the first two.

On the Internet with a wealth of news media Web sites and the rapid dissemination of information, a large percentage of people tend to get their news through major search engines, hence the aim is a story to find readers also through search engines. In a 2011 survey by the Oxford Internet Institute (Dutton \& Blank, 2011) data showed that 61 percent of Internet users in Britain were mainly using a search engine to find information. American Press Institute and the Associated Press-NORC Center for Public Affairs Research found recently (2014) that roughly half of Americans got 
their news from search engines. In another survey, Google was the primary entry point (followed by Facebook) among the top nationally recognized news site brands in the United States, having 30 percent of the traffic to these sites (Olmstead, Mitchell, \& Rosenstiel, 2011). Reuters Institute for the study of Journalism confirms that for news sites search remains crucially important. According to its Digital News Report (Newman \& Levy, 2014) search is still the main gateway in France, Germany, Italy, the US, and Brazil. The behavior of online information seekers is more difficult than the traditional readers. A lot of people look for specific information and their priorities are convenience, rapid access and accuracy (Giussani, 1997). As web technologies constantly change people's reading habits, online journalism finds itself having to chase Web traffic (Tandoc, 2014).

SEO is the process by which Web experts customize a headline, a lede or the text of an article to improve the placement in Google's search results and have a better chance of being read (Stabiner, 2011). Coles (2011) believes that journalists need to think about writing various headlines for every news story. Many Internet-options give editors the ability to continue writing great headlines while benefitting from search engine traffic. It is believed that SEO techniques seem to prefer journalism that deals with breaking news or topical subjects and in contrast, it's more difficult for features and opinion pieces (Richmond, 2008). Despite arguments from media professionals (Richmond, 2008; Usher, 2010) the processes involved in SEO can be significant to the entire online news production chain (Dick, 2011). Journalists are still writing to be read. The highest possible ratings and search engine exploitation are a new reality, an adaptation to the new practices, therefore SEO can be described as a natural part of the journalistic work.

As mentioned, SEO doesn't pertain only to tech experts and it is a skill set for all Web journalists. In this framework, many organizations or educational institutions understanding the value of SEO, offer SEO courses/seminars for journalists and trainee journalists in order to be able to write and publish more effectively for the Web. According to Olander (Knight, 2012), optimization should be baked in during the content creation level in order not to change the editorial structure of the story. During the writing process a journalist must feel creative, combining SEO with quality content production. Usher (2010) mentions that even if an organization has a good SEO strategy, it still needs to be communicated effectively to the newsroom, so journalists don't feel like slaves to Google Trends.

In recent years, many leading online news organizations have employed SEO specialists to do the job. In July 2008 Daily Mail appointed an SEO manager (Oliver, 2008) and in the same year was formed the Guardian's in-house SEO team (Dick, 2011). In late 2009 British Broadcasting Company (BBC) understanding the value of SEO, created for the first time the job of specialist SEO journalist. Within this framework, BBC journalists were trained in basic SEO while one of the most important changes in strategy was the implementation of a dual-headline system that is used up to this day. Journalists have the ability to create two headlines for a story - a short one (31-33 characters) for the front page and other Web site indexes, and a longer one (up to 55 characters) which will appear on the story page itself and in search engine results (Dick, 2011; Asser, 2012). This strategy was taken in order to put more keywords in headline fields. Almost two years later at LATimes, the addition of a SEO chief was one of the key factors leading to traffic success (Ellis, 2011). The same thing happened in many news organizations. Another example is Web edition of Christian Science Monitor, where Search Engine Optimization was a key in order to drive pageviews from 3 million to 25 million per month (Groves \& Brown, 2011). Because Google is many Internet users' front door to the Web, SEO has become a requirement or an obsession for many Web publishers such as Huffington Post (Miller, 2011).

Writing for the Web doesn't mean writing solely for machines. For Asser (2012) it's not just about increasing traffic to a story. Besides, it has to do with the essential needs of Web users to find the information they are looking for and securing long-term promotion for someone's journalism that is not dependent on the few short hours of exposure on a Web index. Paying attention to the audience brings someone in better touch with what the audience cares about (Usher, 2010). The core of journalism is the content per se, how it is written and how it is formed. The same applies to SEO. Creating compelling and useful content will likely influence a Web site more than any of the other factors (Google Starter Guide, 2010). "Value" became an important subconscious factor that will determine how Google perceives Web sites (DeMers, 2013). News organizations have to utilize the chances provided via Web search, understanding the power of SEO to attract-drive traffic from search engines and at the same time help content to be read. Many people talk about a connection between print and online journalism. While media industry have adapted to the digital age and while the competition grow increasingly, the good use of SEO within newsrooms as a powerful tool for attracting more readers, seems to be essential, necessary for (online) journalism.

\subsection{SEO and Social Media}

In today's digital age, social media constitute basic tools for journalists with great influence on media organizations and journalism generally. New media have been established as a space where the news is shared and consumed and an active social media presence/strategy has become a necessity for media industry. SEO is by all means not only link-building and keywords. As the Internet evolves, search engines have become smarter incorporating social content 
into their results and using social networking. The latter has currently become an important piece of SEO strategy and has influence in a business's optimization success. In order to enhance their perfect reach, many search engines integrate Web 2.0 platforms incorporating the information into their searchable indexes (Zimmer, 2008).

Active Facebook profile pages have many ranking possibilities for branded, subject-based, and personal name-based queries at Google. Moreover, results from Twitter can be used for queries where real-time data is helpful. Due to Twitter's domain authority, its profile pages also rank highly for relevant searches (Dover, 2011). Google+ platform has qualities that make it a far superior platform for SEO and sharing content on it has the potential to influence search rankings in significant ways (Shepard, 2013). In their study of Ranking Factors (Peters, 2013) Moz's experts concluded that there is a remarkable correlation between Google $+1 \mathrm{~s}$ and higher search rankings. Factors such as social signals (e.g. facebook shares/likes or how many fans/followers someone has) have become noteworthy to SEO industry and are considered as the new "link building" metric (Frasco, 2013). Recent study from Searchmetrics (2013) revealed how important are social media signals to SEO ranking, especially Google +1 's. Even though, according to Matt Cutts (Slegg, 2014) Google doesn't seem (until now) to be using Facebook and Twitter social signals when it comes to ranking, there are still plenty of benefits and things such as +1 's, shares, likes or the number of followers have definitely a positive impact on Web sites.

Social media and SEO do overlap, and social can help the total organic success of websites in several ways (Pascale, 2014). One of the best ways to create a natural link building is through social media. Links through social media channels are much harder to manipulate, bring real traffic increasing content credibility and thus have significant value. Also the more referrals someone has across the Web, the more search engine spiders notice and categorize his content (Ehrlich, 2013). While social media provide new pathways to journalism, digital journalists must be able to write, report and market their stories and at the same time reporters use SEO to their advantage (Reed, 2013). Social media has transformed the way journalists produce and release news stories and also the way people receive and share information. In our era of electronic communications it's essential for a journalist both to ensure and multiply his online presence on social media sharing his content. A contemporary content, formed in a way appropriate with the requirements of the new era.

\section{Best Practices for Implementing SEO}

As it was mentioned earlier, there is a direct connection between SEO and online journalism. Optimization for search engines is among the key skills that journalists should possess according to the new editorial ethos of Daily Telegraph (Sweney, 2014). Given all the above literature review, the aim of this section is to provide some guidelines or practices that can make journalistic work and Internet journalism generally, more successful and effective in exploiting Web search and also, to show how media professionals can use them in order to improve their visibility in the World Wide Web. In order to create this section, previous-recent studies were taken into account as well as discussions with field experts.

Unfortunately, there is no magic recipe for getting you into the first page of Google and certainly no guaranteed results. On the contrary, there is a variety of things to consider concerning both on-site and off-site optimization that, in conjunction, can bring good results. Some of them can directly affect SEO while others can have an indirect impact on search rank. Whilst there are by all means differences in the ways various search engines work, the basic principles remain similar and a well-planned strategy can usually lead to good results in all major search engines.

This section is divided into two main parts: on-page and off-page optimization. The former includes content optimization together with basic guidelines regarding the architecture and HTML code of a website. The latter pertains to key factors connected with off-page optimization such as links and social media.

\subsection{On-page Optimization}

\subsubsection{Content}

a) Writing titles/headlines

The on-page headline is the first thing a potential visitor is going to view. It is considered as the most important part of a news story. During the writing process try to have in mind the following:

Using main, appropriate words/phrases that people often use in their Web searches (use them wisely) and putting the most search friendly words ahead in order for search engines to «read» them, is crucial to SEO. Frequent usage of proper names and locations (which are search friendly) is also recommended. In order to choose appropriate keywords (keyword research) a number of specialized tools (e.g., Google Keyword Planner) can be used. Furthermore, clear, unique, concise, and descriptive titles are highly important. A title should be accurate, stand - alone and not only for SEO purposes - Generalities (does not help RSS Feeds or bookmarks), abbreviations or acronyms that may not be widely known should be avoided. 
Writing headlines for the internet is different than writing for a print publication. Unlike print media, on the Internet it's hard to control the context of news content. For instance, a headline (or lead paragraph) might appear separately from the whole article elsewhere on a Web site, in the search engine results or even on another Web site (e.g. in someone's Twitter or Facebook streams) and that's why keywords optimization is essential. Some successful titles from the past may not be as effective on the Web nowadays. For example, the famous SUN's "Gotcha" headline from 1982. (Note 3)

Examples:

- World Cup 2014: Brazil humiliated by Germany 7-1 in semi-final (SEO-Friendly)

Germany's triumph in the semi-final (Non-SEO Friendly)

- Novak Djokovic beats Roger Federer in epic Wimbledon 2014 men's final (SEO-Friendly)

Djoko did it again! (Non-SEO Friendly)

b) Different titles/headlines

As mentioned in the literature review, during the headline creation process for an article, it can be helpful for media professionals to think about employing different headlines for dissimilar use for the same news story. This characteristic is used by several big news organizations (e.g., BBC News, Guardian, Huffington Post or New York Times) and the most common practice is the different headlines between front/home page or other Web site indexes and the story page itself (examples from BBC depicted in figure 1). The latter that appears in search engine results, is usually more specific including more keywords for the topic. Others options could be different html title as well as titles for Google news or social media (appropriate for the audience and platform).

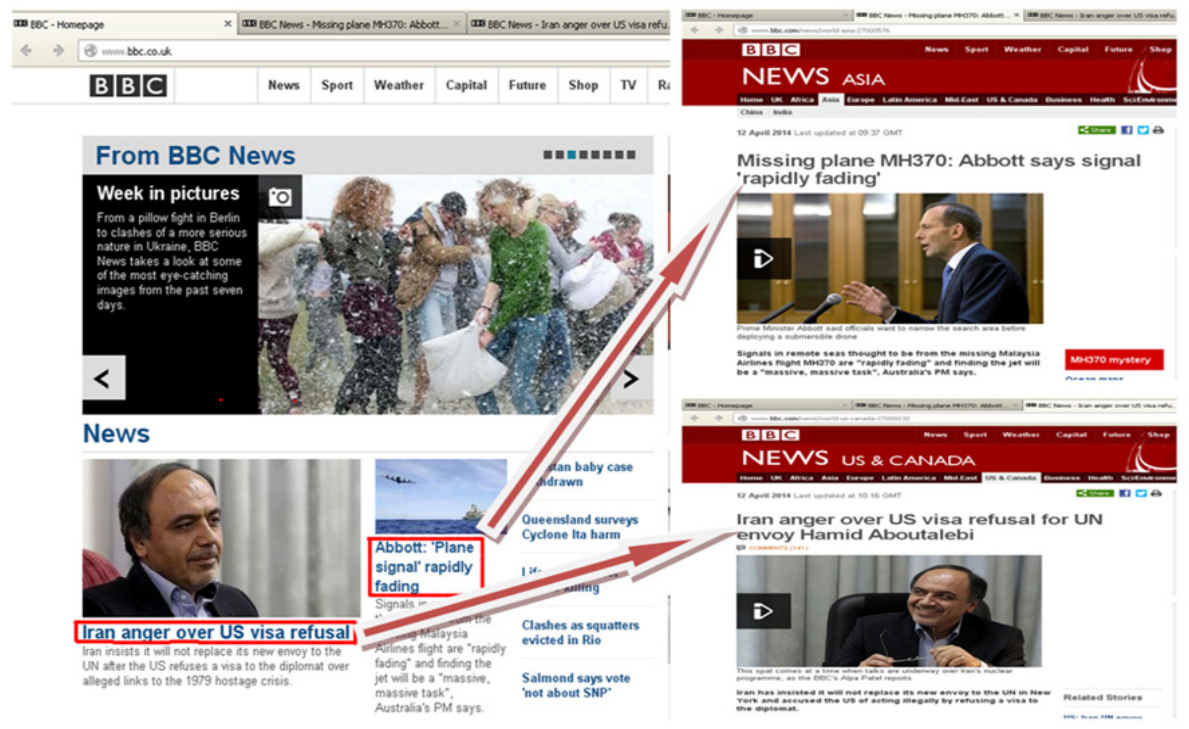

Figure 1. The dual headline system in BBC news

c) First (lede) paragraph

A right headline has to be followed by a good lead paragraph (or "lede" in journalistic jargon). Targeted keywords/phrases should be included naturally in the first paragraph (lead relevance) of the text content. The earlier the keyword is mentioned in the text content, the more (the content) is considered relevant to a search using this keyword. As traditionally happens in journalism (inverted pyramid structure), editors need to continue summarizing the whole story and answering basic questions such as who, when, or where in the first paragraph of their stories. That practice can help search engines see what the rest of someone's page is about.

d) (Alternative) Ways of writing content

Apart from keywords that people often use or may use in their searches about an exact topic, it can be useful for content writers to employ words/phrases which are connected with the story and search engines «wait» to «see» them within the article. Users who know a lot about the topic might use different keywords in their queries (different search behaviors or synonyms should be taken into account). It is extremely important to have in mind that the use of keywords to a great extent in the actual content of a Web page is certainly not a key requirement. On the contrary, it is effective when this happens naturally without boring the readers. Keyword stuffing can bring unpleasant results to a Web site. 
In addition:

- As already mentioned, close attention need to be paid in abbreviations, nicknames and acronyms. Using full terms or trying to get as close as possible to the exact search query and language that most of visitors/search engine users will use, is a common SEO practice. Unlike print media, journalists should avoid playing with words. Writing simply and clearly is important on the Internet. Metaphors or other forms of wordplay are not comprehensible by search engines.

- Keeping the content fresh. Fresh content generates traffic and improves search rankings (duplication of content should be avoided). Furthermore, it is good for editors to write many different articles/posts and make frequent updates on a subject instead of a long story. Contrary to print media, long stories bore readers on the Web. If there are previous articles on the same topic, adding links to them (internal linking) with relevant keywords in the hyperlink text (anchor text) rather than "for more information click here", is preferable. Anchor texts give content producers a way to add relevance to their pages and search engines look at this text to deduce how relevant a page is to those words.

e) Video (or multimedia) content

The addition of relevant, video content apart from the main text adds value, makes content even richer and it is often ranked better/higher from search engines (DeMers, 2013). It is said that video content attract and engage users more, since it is considered to be highly shareable having a higher clickthrough (Note 4) rate than traditional text results (Dover, 2011). More than 1 billion unique users every month visit the most popular video Web site, YouTube (which is also considered as an alternative search engine) (Note 5). Furthermore, YouTube drives the most engaged traffic with the lowest average bounce rate (Note 6) and the longest visit duration among social media platforms (Wong, 2014). As a consequence, it can be characterized as a valuable tool to reach a large audience, get traffic and thus it is recommended for a media company to create a YouTube channel. It is worth mentioning that is owned by Google and is integrated in its search results.

\section{f) Content Marketing and Qualitative Content}

Unlike previous years when link building and similar strategies were the big deal, recent algorithm changes from search engines especially in Google updates (Penguin, Panda and Hummingbird) (Note 7) make experts recommend and pay special attention to the general public, quality and content marketing. Content marketing attracts backlinks, adds value for the reader and many experts have called it as the new SEO (DeMers, 2013). Undeniably, the most important and obvious optimization factor is the content per se that is created and written primarily for people, not for search engines. SEO is not only about engines but also making someone's site better for people. It is usually said that the content is the king for any Web site and especially these days where the redundancy of information or the lack of attention dominates, this has to be interesting, reliable, up to date with new ideas and perspectives. Even the search engines look for unique (subject/content uniqueness), qualitative and useful content (information rich) that will satisfy and motivate readers to share it. As previously mentioned Google and other search engines got much smarter and can distinguish between content with real value and content that exists only for SEO purposes. This constitutes a long-term profit.

Regardless of how good is SEO, it is not likely for any Web site with useless content to get ranked well in the long run because no one is ever going to visit or look for it. Users know good content and will likely want to share it through social networks, blog posts or forums. Besides the fact that search engines tend to look at certain parts of a Web page (page title, description etc.), a journalist - Web producer should know his internet audience and write quality, useful content that people actually want to read. New techniques designed to ensure high ranking, need to be implemented having in mind the traditional news values. Professional quality content still remains necessary and as a consequence, the role of the journalist who knows and is trained to write for people is more important than SEO.

\subsubsection{HTML}

\section{a) Page Titles - Html title tag (Note 8)}

The general rules of on-page headlines apply also for html title tags. Most of the time Web sites and their content management systems (CMS) automate the creation of the HTML title tag using on-page headline. Html titles are important because they usually appear in search engine results or in the browser title bar. Major search engines pay a lot of attention to words that appear in the titles. Thus, titles are considered as one of the most important on-page SEO elements (experts recommend 55 characters as the title-length limit, including spaces).

b) Right description of Web page - Meta description tag (Note 9)

Adding description meta tags to Web pages is a good practice and is highly recommended because they are commonly used by Google as snippets/preview for someone's web pages on SERPs (Figure 2). Journalists and Web editors should write unique descriptions, concise-accurate descriptions of the content of Web pages that draw attention (intriguing) and let searchers know exactly whether the given page contains the information they're looking for. The existence of 
relevant keywords that are connected with the title words is also essential. Many Web sites insert the first sentence of any news story into description. It is considered that the right meta description length is between 150-160 characters including spaces.

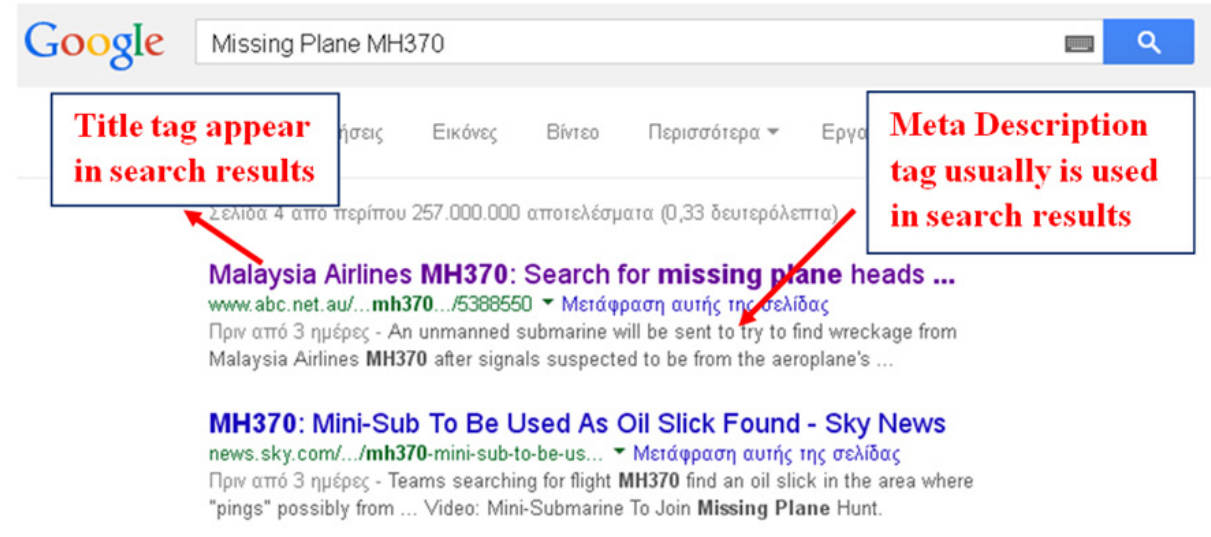

Figure 2. Html Title tag and Meta Description in search results

c) Meta keywords tag (Note 9) and Google News

Many Web sites continue to place keywords in meta keywords tag even if it is currently no longer important to Google and thus SEO. Nevertheless, if they are used properly (appropriate words), those keywords may have a positive impact. Also, recent Google updates have amplified visibility of hashtags (e.g. \#seo) in organic search results (Slegg, 2013; Murtagh, 2013) therefore they can be useful in content optimization.

Google News is one of the most popular news sources all over the world and many people use it to access information about current affairs on a daily basis. Beyond doubt, many of the SEO practices also apply to Google News. Google news aggregator gives priority to fresh, informative- substantial content that focus on the topic (relevancy) and lead a story cluster (articles on a particular topic). In addition, it is essential for the content to be original, unique and covers the basic journalistic principles. Except for keywords tag, about two years ago Google announced the news_keywords metatag that is used for Google news. This new feature helps Google News to better understand the article content without forcing the editors to water down the creativity of a great headline (Galfi, 2012). The new metatag can include terms that don't need to appear anywhere within the headline or body text.

Example:

In a story about tennis and ATP World Finals at Guardian.com titled "Roger Federer pulls out of ATP Tour Finals with back injury" we have the following elements:

- Meta description tag: Roger Federer pulled out of his final showdown with Novak Djokovic at the ATP World Finals in London.

- Keywords and also news_keywords are the same: Roger Federer, ATP World Tour Finals, Novak Djokovic, Andy Murray, Sport, Tennis, Sport

d) Image optimization

Using relevant keywords that describe the image within 1) file names or 2) alt text/tags can help search engines determine what the image is about. A journalist or content producer in general, doesn't have to be a developer to complete them because most Content Management Systems (CMSs) allow him to enter text for the alt-tag and title attribute. This kind of optimization is very important, especially for image-based search engines such as Google Images. The use of captions is also recommended.

Example:

In an article titled "Microsoft Fixes 19-Year-Old Windows Bug" at Huffington Post the article image has the following characteristics:

- the file name ends with: ..../n-MICROSOFT-WINDOWS-large570.jpg

- Associated text: MICROSOFT WINDOWS

e) Text formatting

Plenty of paragraphs and sub-headings can help search engines scan effectively the content. In this context, formatting 
text/articles in a way recognizable by search engines (and wisely) can be useful. Headings tags $\mathrm{h} 1$, $\mathrm{h} 2$ or bold can emphasize important information (with top keywords) and make text structure more readable for users giving the same format someone expect from a normal book. H1 tag is the more important and it is good to be as high as possible (with top keywords) within the page. The system of search engines examines how the text of the article is formatted using these tags to determine how important words are on the page.

\subsubsection{Architecture}

\section{a) Uniform Resource Locator (URL)}

Using appropriate, right keywords in URLs is certainly SEO-friendly. Most editors use keywords from the title or the lead paragraph in order to create an information consistency. Search engines prefer websites with consistent and easy-to-read URLs. These have to show the path that leads to a specific web page and also the section of a website that someone reads.

\section{Examples:}

- In a story entitled "Modern slavery affects more than 35 million people, report finds" at theGuardian.com, the URL address is:

http://www.theguardian.com/world/2014/nov/17/modern-slavery-35-million-people-walk-free-foundation-report

- Also, in a story entitled "Amazon Moves to Extend Cloud-Computing Dominance" at NYTimes, the URL is:

http://www.nytimes.com/2014/11/17/business/amazon-moves-to-extend-cloud-computing-dominance.html

The following forms of addresses should be avoided:

- http://www.urlsandseo.gr/shop/item.aspx?itemid=3051

- http://www.urlsandseo.gr/forum/viewtopic/m-159327.html

- http://www.newsandseo.gr/B7TJ5OG/28296-2014-11

b) Crawlability, navigation and speed

Those factors can be clearly characterized as of technical nature and don't concern content producers. Technical experts need to use various ways to improve the crawl efficiency. A right, internal link-navigation structure (avoid/fix broken links) helps visitors quickly find the content they want (user-friendly). Besides, it enables search engines to browse all the pages on a Web site and also to understand what content the publisher thinks is important. Furthermore, it is by all means essential for a Web site and thus Web content, to be accessible for mobile devices that are very popular these days. Another factor that impacts search ranking and is taken into account by search engines algorithms (especially Google) in recent years, is site speed. Site speed reflects how quickly a website responds to web requests. This factor should be a priority for site owners because faster web sites satisfy internet users providing a better experience and as a consequence can increase the overall traffic. On the contrary, slow web sites decrease customer satisfaction and visitors spend less time there.

\subsection{Off-page Optimization}

\subsubsection{Attracting Many and Qualitative Inbound Links}

As mentioned, links from other Web sites have great significance, serve as votes for the value and constitute a basic requirement in order for a Web site to be found both from search engines and Web searchers. Search engines definitely like links. Furthermore, it is extremely important for inbound links to be qualitative, coming from popular/established Web sites so as to give bigger value and better evaluation. Strong links survive. For a Web site with quality content it is usually a matter of time before it acquires by itself many natural and qualitative backlinks. Natural links through text content without planning, as well as the variety of their sources are important factors. However, there are many different ways it can be used to gain inbound links such as articles/domain submission to directories (Dmoz for example), forum, blogs, and news aggregators.

Not only inbound links, but also those that lead to other relevant Web pages (preferably credible and high-ranking sites) can contribute positively to SEO especially if a Web site is new. External links within an article can cover even more a topic giving further information to the readers. However exaggerations are not needed and may harm someone's Web page.

\section{- Links/Articles Exchange}

Links (articles) exchange (or reciprocal links) and cooperation between two Web sites especially among sites with relevant content can help in building more qualitative inbound links and also in bringing traffic and Pagerank increase. It is a common tactic for media Web sites, especially when there is a lack of staff and a number of thematic categories 
cannot be covered properly.

\subsubsection{Authority, Trust and History}

Backlink profile, quality and also website's history are factors that affect website's authority and trust to a great extent. Search engines tend to prefer older content (that is established Web sites) and rank higher older domains. Those domains can carry more weight due to their history and backlinks pointing to them. Apart from trying to create quality content, it is useful for news websites to keep the domain name and URLs the same and permanent in the long term.

\subsubsection{The Power of Social Media}

As already stated, social networks are increasingly affecting search engines' algorithms and many experts considered them to be a notable part of SEO. Search engines have become smarter and social signals have already started to play their role in SEO. The extent of social's impact on search is evolving and "social signals" are now the fastest-rising search engine ranking factor (DeMers, 2014) as search engines determine how to leverage our social interaction and behavior (Search Engine Land's Guide To SEO 2013). It is true that, corporate reputation can be enhanced through social-media activity (Bor, 2014). Therefore, if someone is a journalist or a content producer, he has to ensure his active online presence (interacting with people is very important), sharing his work and fully utilizing social media channels along with their tools and services. The motto is "keep up to date, become part of a community".

\subsubsection{Web Analytics, "Ht" Tpics and Sarch Tends}

People working on media have to be aware of current events and what people search for utilizing useful tools (e.g., Google trends, news aggregators such as Google news, newsmap.jp, Digg or social Topsy and Reddit) in order to identify "hot" topics, see popular search terms and why not along with their own news agenda find story ideas for news writing. In the past, journalists have feedback only from a particular, committed audience. Today, with Web analytics (e.g., Google Analytics) they have the ability to collect valuable information about what happens after publication, better understand their audience (what content make a difference in engagement), the impact of their job and if an article is successful as well as find reliable sources or ideas for writing. In addition, news organizations can determine their search engine exposure by finding their organic search traffic. As a consequence and apart from all the above, these data can help media professionals decide what topics to cover and to what extent.

\section{Conclusions and Future Extensions of the Work}

Search Engine Optimization (SEO) is directly connected with the visibility of a Web site in a search engine's organic search results. More specifically, the higher and more frequent a site appears in the list, the more visitors it will receive from the search engine's users. New Internet technologies and Web 2.0 have changed basic journalistic work processes over the last years and challenged traditional journalism (Spyridou \& Veglis, 2008; Chung, 2008). In this paper we examined SEO and the opportunities provided through Web search in the context of online journalism and media Web sites. According to scholars, it is obvious that this kind of optimization along with search engines in general, have a significant impact on journalistic work (Richmond, 2008; Dick, 2011) and form an important part of skills and knowledge in the field of online communications. Furthermore, we proposed and discussed SEO guidelines that can make journalistic work and Internet journalism generally, more effective and contemporary.

SEO will always have a place in a Web strategy as long as there are search engines. As years pass, there is no doubt that search engines will continue to evolve their algorithms. Given that there will always be a need for search, organizations will continue to figure out ways to use SEO-related techniques for higher rankings. Social media have increasingly become one of the many factors search engines take into account (Zimmer, 2008; Dover, 2011). SEO experts see a shift away from traditional ranking factors to deeper analysis and factors such as content marketing, authorship and social signals (DeMers, 2013).

The evolution of the Internet and Web technologies is by all means influencing mass media. For news sites search remains crucially important. As long as Google and other search engines continue to drive traffic to media Web sites, basic SEO knowledge can be a useful tool for media organizations and journalists whose work appears online. All they have to do in order to stay current and gain better exposure on search engines is to possess the new practices and use them to their advantage. Media professionals need to take advantage of social media by understanding the culture of online news consumption, as well as the search habits of their readership, and distribute the news in a synchronized way. Moreover, news organizations have to be anywhere, at anytime, on any platform (Picard, 2009). While media industry have adapted to the digital age the good use of SEO within newsrooms seems to be essential and necessary for online journalism.

Beyond argument, there are several important aspects in this area that require further study. A future extension of this work will include a survey of online media concerning the usage of SEO techniques that are being employed. Also comparative studies with foreign online media as well the major media players are also something that must be 
considered in the near future. Last but not least the increasing involvement of social media in the SEO techniques is something that deserves more study in order to clarify the relation between them.

\section{References}

American Press Institute. (2014). The Personal News Cycle: How Americans choose to get their news. The research was conducted by the Media Insight Project-American Press Institute and the Associated Press-NORC Center for Public Affairs Research. http://www.americanpressinstitute.org/publications/reports/surveyresearch/how-americans-get-news/

Anderson, C. (2009). Web Production, News Judgement, and Emerging Categories of Online Newswork in Metropolitan Journalism. 10th International Symposium on Online Journalism, University of Texas, Austin.

Asser, M. (2012). Search Engine Optimisation in BBC News [Web log post]. http://www.bbc.co.uk/blogs/internet/posts/search_engine_optimisation_in

Bor, E. S. (2014). The Link between Social Media Activity and Corporate Reputation. http://www.forbes.com/sites/onmarketing/2014/07/14/the-link-between-social-media-activity-and-corporate-reputa tion/

Charlton, C., Blank, R., Otuome, H., \& Gonzalez, O. (2008). AdvancED Flex Application Development, New York: Apress.

Chitika Online Advertising Network, (2013). The Value of Google Result Positioning. http://chitika.com/google-positioning-value

Chung, S. D. (2008). Interactive features of online newspapers: Identifying patterns and predicting use of engaged readers. Journal of Computer-Mediated Communication, 13(3), 658-679.

Coles, M. (2011). How to: write headlines that work for SEO. http://www.journalism.co.uk/skills/how-to-write-headlines-that-work-for-seo/s7/a545817/

Cutts, M. (2012). Another step to reward high-quality sites [Web log post]. http://insidesearch.blogspot.gr/2012/04/another-step-to-reward-high-quality.html

DeMers, J. (2013). SEO in 2013: 7 Surprisingly Simple Factors That Will Take The Lead. http://www.searchenginejournal.com/seo-in-2013-7-surprisingly-simple-factors-that-will-take-the-lead/57092/

DeMers, J. (2014). The Three Pillars of SEO in 2014. Forbes. http://www.forbes.com/sites/jaysondemers/2014/01/28/the-three-pillars-of-seo-in-2014/

Dick, M. (2011). Search Engine Optimisation in UK News Production. Journalism Practice, 5(4), 462-477.

Dover, D. (2011). Search Engine Optimization Secrets. Indianapolis: Wiley

Dutton, H. W., \& Blank, G. (2011). Next Generation Users: The Internet in Britain. Oxford Internet Survey 2011 report. Oxford Internet Institute, University of Oxford. http://www.oii.ox.ac.uk/news/?id=598

Ehrlich, S. (2013). SEO Best Practices: The Impact of Social Media on Search Engine Optimization. Bulldog reporter. http://www.bulldogreporter.com/dailydog/article/thought-leaders/seo-best-practices-the-impact-of-social-media-on -search-engine-opti

Ellis, J. (2011). Traffic Report: Why pageviews and engagement are up at Latimes.com. NiemanLab. http:/www.niemanlab.org/2011/08/traffic-report-why-pageviews-and-engagement-are-up-at-latimes-com/

Frasco, S. (2013). 6, Reasons Social Media Is Critical To Your SEO. $\mathrm{http}: / / \mathrm{www}$.socialmediatoday.com/content/6-reasons-social-media-critical-your-seo

Galfi, R. (2012). A newly hatched way to tag your news articles. http://googlenewsblog.blogspot.gr/2012/09/a-newly-hatched-way-to-tag-your-news.html

Galitsky, B., \& Levene, M. (2004). On the economy of Web links: Simulating the exchange process. First Monday, 9(1). http://firstmonday.org/ojs/index.php/fm/article/view/1109/1029

Giussani, B. (1997). A New Media Tells Different Stories. First Monday, 2(4).

http://firstmonday.org/ojs/index.php/fm/article/view/521/442

Google. (2010). Search Engine Optimization Starter Guide.

http://static.googleusercontent.com/external_content/untrusted_dlcp/www.google.co.jp/ja/jp/intl/en/webmasters/do cs/search-engine-optimization-starter-guide.pdf

Groves, J., \& Brown, C. (2011). Stopping the Presses: A Longitudinal Case Study of the Christian Science Monitor 
Transition From Print Daily to Web Always. The Official Research Journal of the International Symposium on Online Journalism, 1(2). https://online.journalism.utexas.edu/2011/papers/GrovesBrown2011.pdf

Hoell, C. (2013). SEO vs PPC. What's the difference? [Web log post]. http://www.mycommerce.com/blog/item/156-seo-vs-ppc-what $\% \mathrm{E} 2 \% 80 \% 99$ s-the-difference

Iprospect (2006). Search Engine User Behavior Study. http://district4.extension.ifas.ufl.edu/Tech/TechPubs/WhitePaper_2006_SearchEngineUserBehavior.pdf

Knight, E. (2012). The role of the journalist in SEO is changing [Web log post]. http://www.editorsweblog.org/2012/08/01/the-role-of-the-journalist-in-seo-is-changing

Ledford, L. J. (2009). Search Engine Optimization Bible, second edition, Indianapolis: Wiley.

Lieberam-Schmidt, S. (2010). Analyzing and Influencing Search Engine Results, Business and Technology Impacts on Web Information Retrieval, Gabler.

Miller, C. C. (2011). Web Words That Lure the Readers. NYtimes. http://www.nytimes.com/2011/02/11/business/media/11search.html?_r=0

Murtagh, R. (2013). The role of \#hashtags in social media and search, http://searchenginewatch.com/article/2305444/The-Role-of-Hashtags-in-Social-Media-and-Search

Newman, N., \& Levy A. L. D. (2014). Reuters Institute Digital News Report 2014 - Tracking the future of news. Oxford: Reuters Institute for the Study of Journalism, University of Oxford. https://reutersinstitute.politics.ox.ac.uk/sites/default/files/Reuters\%20Institute\%20Digital\%20News\%20Report\%2 02014.pdf

Nigro, O. H., Balduzzi, L., Cuesta, A. I., \& Cisaro, E. G. S. (2012). Knowledge Based System for Intelligent Search Engine Optimization. In Ford Lumban Gaol (ed.), Recent Progress in Data Engineering and Internet Technology, 65-72. Berlin: Springer.

Oliver, L. (2008). Mail Online Names Simon Schnieders as Search Strategy Head. http://www.journalism.co.uk/news/mail-online-names-simon-schnieders-as-search-strategy-head/s2/a531917/

Olmstead, K., Mitchell, A., \& Rosenstiel, T. (2011). Navigating News Online: Where People Go, How They Get There and What Lures Them Away. Pew Research Center's Project for Excellence in Journalism. http://www.journalism.org/2011/05/09/navigating-news-online/

Pavlik, V. J. (1997). The future of online journalism, Columbia Journalism Review, July/August 1997.

Peters, M. (2013). 2013 Search Engine Ranking Factors (Moz's study). http://moz.com/blog/ranking-factors-2013

Pew Research Center for the People \& the Press, (2013). Amid Criticism, Support for Media's 'Watchdog' Role Stands Out. http://www.people-press.org/2013/08/08/amid-criticism-support-for-medias-watchdog-role-stands-out/

Picard, R. (2009). Blogs, Tweets, Social Media and the News Business. Nieman Reports, 63(3), 10-12. http://www.nieman.harvard.edu/reports/article/101884/Blogs-Tweets-Social-Media-and-the-News-Business.aspx

Potts, K. (2007). Web Design and Marketing Solutions for Business Websites, New York: Apress

Reed, M. (2013). Nine challenges facing the future of journalism [Web log post]. http://ijnet.org/blog/nine-challenges-facing-future-journalism

Richmond, S. (2008). How SEO is changing journalism. British Journalism Review, 19(4) 51-55.

Safran, N. (2013). 310 Million Visits: Nearly Half of All Web Site Traffic Comes From Natural Search (Data). http://www.conductor.com/blog/2013/06/data-310-million-visits-nearly-half-of-all-web-site-traffic-comes-from-nat ural-search/

Searchmetrics, (2013). Search Metrics Ranking Factors and Rank Correlation. http://www.searchmetrics.com/en/knowledge-base/ranking-factors-us-2013/

Shepard, C. (2013). Amazing Correlation between Google 1s and higher search rankings [Web log post]. http://moz.com/blog/google-plus-correlations

Slegg, J. (2013). Hashtags Come to Google Search Results. http://searchenginewatch.com/article/2297394/Hashtags-Come-to-Google-Search-Results

Slegg, J. (2014). Matt Cutts: Facebook, Twitter Social Signals Not Part of Google Search Ranking Algorithms. Search Engine Watch, 
http://searchenginewatch.com/article/2325343/Matt-Cutts-Facebook-Twitter-Social-Signals-Not-Part-of-Google-S earch-Ranking-Algorithms

Spyridou, P., \& Veglis, A. (2008). Exploring structural interactivity in online newspapers: A look at the Greek Web landscape. First Monday, 13(5). http://firstmonday.org/ojs/index.php/fm/article/view/2164/1960\#17

Spyridou, P., \& Veglis, A. (2012). Sustainable Online News Projects: Redefining Production Norms and Practices. Proceedings of the 10th World Media Economics and Management Conference, Thessaloniki, May.

Stabiner, K. (2011). CJR Column Mentions The Simpsons. A second look at SEO. Columbia Journalism Review, March/April 2011. http://www.cjr.org/feature/cjr_column_mentions_the_simpsons.php?page=all

Sweney, M. (2014). Telegraph to use digital content as backbone of paper. The Guardian. http://www.theguardian.com/media/2014/oct/07/telegraph-overhaul-editorial

Tandoc Jr, C. E. (2014). Journalism is twerking? How web analytics is changing the process of gatekeeping. New Media \& Society, 16(4) 559-575.

Usher, N. (2010). What impact is SEO having on journalists? Reports from the field. Nieman Journalism Lab. http://www.niemanlab.org/2010/09/what-impact-is-seo-having-on-journalists-reports-from-the-field/

Wong, D. (2014). YouTube, Google and LinkedIn Drive The Most Engaged Social Referrals. http://blog.shareaholic.com/social-media-traffic-engagement-03-2014/

Zimmer, M. (2008). The Externalities of Search 2.0: The Emerging Privacy Threats when the Drive for the Perfect Search Engine meets Web 2.0. First Monday, 13(3).

http://firstmonday.org/ojs/index.php/fm/article/view/2136/1944

Notes

Note 1. Also called «natural» or un-paid. The results that appear because of their relevance to the search terms in contrast with paid advertisements.

Note 2. http://en.wikipedia.org/wiki/Pay_per_click

Note 3. http://www.bl.uk/onlinegallery/features/frontpage/gotcha.html

Note 4. A ratio showing how often people who see an advertisement/link end up clicking it. Read more at http://en.wikipedia.org/wiki/Click-through_rate or https://support.google.com/adwords/answer/2615875?hl=en

Note 5. http://www.youtube.com/yt/press/

Note 6. The percentage of single-page visits (visitors who enter the site and leave without viewing other pages or interacting within the same site).

Note 7. http://www.searchenginejournal.com/seo-guide/google-penguin-panda-hummingbird

Note 8 . HTML title or $<$ title $>$ tag is a section of HTML code that every page should have. It defines the title of the HTML document and contains the name of the web page.

Note 9. Read the keywords attribute and the description attribute at

http://en.wikipedia.org/wiki/Meta_element\#The_keywords_attribute

$(\mathrm{cc}) \mathrm{BY}$

This work is licensed under a Creative Commons Attribution 3.0 License. 